\title{
ANALISIS STRUKTURISASI KELEMBAGAAN DESA MANDIRI PANGAN BERKELANJUTAN DENGAN APLIKASI METODE INTERPRETATIVE STRUCTURAL MODELLING (ISM) DI KABUPATEN BENGKULU TENGAH
}

\author{
INSTITUTIONAL STRUCTURING ANALYSIS OF MANDIRI VILLAGE \\ INSTITUTION SUSTAINABLE WITH APPLICATIONS INTERPRETATIVE \\ STRUCTURAL MODELING (ISM) IN BENGKULU CENTRAL
}

\author{
Herri Fariadi \\ Program Studi Agribisnis Fakultas Pertanian Universitas Dehasen Bengkulu \\ Email herrifariadi@gmail.com
}

\begin{abstract}
ABSTRAK
Penelitian ini bertujuan mengidentifikasi atribut-atribut yang berpengaruh terhadap struktur kelembagaan desa mandiri pangan berkelanjutan dan untuk merumuskan bagaimana struktur kelembagaan yang terlibat dalam pengembangan desa mandiri pangan agar dapat berkelanjutan di Kabupaten Bengkulu Tengah. Penelitian ini dilaksanakan pada bulan Januari-Februari 2015. Penentuan lokasi penelitian ini dilakukan secara sengaja (purposive) yakni di Kabupaten Bengkulu Tengah dengan pertimbangan bahwa Kabupaten Bengkulu Tengah merupakan kawasan yang telah mendapat program desa mandiri pangan, juga didasarkan atas pertimbangan bahwa Kabupaten Bengkulu Tengah memiliki potensi untuk dikembangkan lebih lanjut.Responden dalam penelitian ini adalah kalangan pakar terpilih yang diambil berdasarkan kesesuaian keahlian dengan struktur dan kelembagaan usaha pangan. Pada saat penentuan atribut, responden diambil sebanyak 17 orang, selanjutnya dalam metode interpretative structural modelling (ISM) untuk penentuan struktur kelembagaan responden yang diambil sebanyak 5 orang yang berasal dari akademisi. Analisis atribut-atribut yang berpengaruh terhadap struktur kelembagaan desa mandiri pangan berkelanjutan dilakukan dengan pendekatan Multi-Dimensional Scaling (MDS) yang disebut dengan pendekatan Rap-Demangan. Untuk merumuskan struktur kelembagaan menggunakan Interpretative Structural Modeling (ISM). Hasil analisis Rap-Demangan menunjukkan bahwa indeks keberlanjutan kelembagaan di Kabupaten Bengkulu Tengah dengan kategori baik (75.6) dalam skala keberlanjutan 0-100. Hasil Output ISM-Strella, berdasarkan Reachability Matrix (RM) Lembaga Sosial, berada pada sektor I (AUTONOMOUS), sektor II (DEPENDENT) di tempati oleh Pengolah Hasil Pangan, Pemasar Hasil Pangan, Kelompok Tani/Ternak/Nelayan, Koperasi dan UKM, Lembaga Keuangan Mikro, Gapoktan, KTNA, Unit Pembenihan Rakyat, Sedangkan yang berada pada sektor III (LINKAGE) yaitu adalah Pembudidaya Pangan, Disperindag. Pada sektor IV (INDEPENDENT) yaitu adalah Kementrian Pertanian, Dinas Teknis, Badan Ketahanan Pangan, BP4K, Tokoh Masyarakat, Kementrian Kelautan Dan Perikanan, Balai Pembibitan, Balai Benih Ikan, Bappeda, Dinas Pekerjaan Umum, Penyuluh.
\end{abstract}

Kata Kunci : struktur kelembagaan, desa mandiri pangan berkelanjutan, metode Interpretative Structural Modeling (ISM). 


\begin{abstract}
This study aims to identify attributes that influence the institutional structure of sustainable food villages and to formulate how institutional structures are involved in the development of food self-sufficient villages to be sustainable in Central Bengkulu Regency. This research was conducted in January-February 2015. The determination of the location of this research was purposive in Central Bengkulu Regency with the consideration that Bengkulu Tengah Regency is an area that has got the self-supporting village program of food, also based on the consideration that Bengkulu Tengah Regency has Potential to be developed further. The correspondents in this study were selected experts who were taken on the basis of suitability of skills with the structure and food business institutions. At the time of determining the attributes, respondents were taken as many as 17 people, then in the method of interpretative structural modeling (ISM) for the determination of institutional structure of respondents taken as many as 5 people from academia. The analysis of attributes that influence the institutional structure of self-sustaining food village is done by Multi-Dimensional Scaling (MDS) approach called Rap-Demangan approach. To formulate institutional structures using Interpretative Structural Modeling (ISM). Rap-Demangan analysis result shows that institutional sustainability index in Bengkulu Tengah Regency with good category (75.6) in sustainability scale 0-100. The Output Results of ISM-Strella, based on the Reachability Matrix (RM) of Social Institutions, are in sector I (AUTONOMOUS), sector II (DEPENDENT) is occupied by Food Processors, Marketers, Farmers / Fishermen, Cooperatives and SMEs, Micro Finance Institution, Gapoktan, KTNA, Community Hatchery Unit, while those in sector III (LINKAGE) are Food Cultivator, Disperindag. In sector IV (INDEPENDENT) are Ministry of Agriculture, Technical Service, Food Security Agency, BP4K, Public Figure, Ministry of Marine and Fisheries, Breeding Center, Fish Seed Center, Bappeda, Department of Public Works,
\end{abstract}

Keywords: institutional structure, self sustainable food village, Interpretative Structural Modeling (ISM) method.

\section{PENDAHULUAN}

\section{Latar Belakang}

Pembangunan berkelanjutan adalah usaha untuk memenuhi kebutuhan sekarang tanpa mengurangi kemampuan generasi yang akan datang untuk memenuhi kebutuhan mereka (Abdoellah, 2010).

Untuk mencapai tujuan pembangunan berkelanjutan, ada sejumlah syarat yang harus dipenuhi. Pertama, peningkatan potensi produksi dengan pengelolaan yang ramah lingkungan. Kedua, menjamin terciptanya kesempatan yang merata dan adil bagi orang. Dengan dua syarat tersebut, pembangunan berkelanjutan adalah pembangunan ekonomi yang harus berwawasan lingkungan dan sekaligus mengusahakan pemerataan yang adil (Setiadi dkk, 2008; Dewi, 2011; Yusvianty, 2010).

Prinsip dasar pelaksanaan program desa mandiri pangan adalah upaya mengatasi kerawanan pangan dan kemiskinan melalui proses pemberdayaan masyarakat 
untuk mengenali potensi dan kemampuannya, mencari alternatif peluang dan pemecahan masalah serta mampu mengambil keputusan untuk memanfaatkan sumberdaya alam secara efisien dan berkelanjutan sehingga tercapai kemandirian pangan (BKP, Kementa, 2012).

Bengkulu Tengah merupakan salah satu kabupaten program desa mandiri pangan yang dilaksanakan di Provinsi Bengkulu. Salah satu permasalahan dan tantangan dalam ketahanan pangan adalah masih terbatasnya prasarana dan sarana serta kelembagaan usaha di bidang pangan, (BKP, Kementan, 2012). Maka diperlukan kajian mengenai strukturisasi kelembagaan desa mandiri pangan berkelanjutan di Kabupaten Bengkulu Tengah.

\section{Tujuan}

Penelitian ini bertujuan mengidentifikasi atribut-atribut yang berpengaruh terhadap struktur kelembagaan desa mandiri pangan berkelanjutan dan untuk merumuskan bagaimana struktur kelembagaan yang terlibat dalam pengembangan desa mandiri pangan agar dapat berkelanjutan di Kabupaten Bengkulu Tengah.

\section{METODE PENELITIAN}

\section{Tempat dan Waktu}

Penelitian ini dilaksanakan pada bulan Januari-Februari 2015. Penentuan lokasi penelitian ini dilakukan secara sengaja (purposive) yakni di Kabupaten Bengkulu Tengah dengan pertimbangan bahwa Kabupaten Bengkulu Tengah merupakan kawasan yang telah mendapat program desa mandiri pangan, juga didasarkan atas pertimbangan bahwa Kabupaten Bengkulu Tengah memiliki potensi untuk dikembangkan lebih lanjut.

\section{Pengambilan Sampel}

Responden dalam penelitian ini adalah kalangan pakar terpilih yang diambil berdasarkan kesesuaian keahlian dengan struktur dan kelembagaan usaha pangan. Responden-responden tersebut berasal dari berbagai dinas/instansi dan kalangan profesional, antara lain Akademisi, Badan Ketahanan Pangan, Dinas Teknis terkait, Bappeda, PPL, Tokoh masyarakat dan Gapoktan atau kelompok tani dan lembaga lain yang berada di wilayah penelitian. Pada saat penentuan atribut yaitu dengan survai pakar, responden diambil sebanyak 17 orang, selanjutnya dalam metode interpretative structural modelling (ISM) untuk kelembagaan responden yang diambil sebanyak 5 orang yang berasal dari akademisi. 


\section{Jenis dan Sumber Data}

Data yang diperlukan, diambil dari dua sumber yaitu data primer dan data sekunder.

\section{Analisis Data}

Untuk mengetahui Bagaimana struktur kelembagaan yang terlibat dalam pengembangan desa mandiri pangan agar dapat berkelanjutan, dilakukan dengan analisis Interpretative Structural Modeling (ISM) Namun terlebih dahulu menganalisis atribut-atribut yang sensitif berpengaruh terhadap indeks dan status keberlanjutan pengembangan desa mandiri pangan dari aspek hukum dan kelembagaan yaitu dengan menggunakan analisis Multi Dimensional Scaling (MDS).

\section{HASIL DAN PEMBAHASAN}

\section{Hasil Analisis Ordinasi dan Analisis Leverage Kelembagaan}

Atribut-atribut yang memberikan pengaruh terhadap tingkat keberlanjutan pada dimensi infrastruktur dan teknologi terdiri dari (1) sarana dan prasarana penyuluhan, (2) dukungan sarana prasarana umum, (3) teknologi ramah lingkungan, (4) sumber air bersih dan ketersediaan untuk pemukiman, (5) infrastruktur penasaran produk, (6) penggunaan teknologi pengolahan usahatani, (7) ketersediaan energy listrik, (8) keberadaan saluran irigasi, (9) jalan penghubung antar desa dan desa kota, dan (10) jalan usahatani.

Berdasarkan nilai ordinasi kelembagaan yang merupakan hasil olahan dengan RapDemangan diketahui nilai indeks keberlanjutan pada pengembangan desa mandiri pangan di Kabupaten Bengkulu Tengah yaitu sebesar 75,6 dalam skala keberlanjutan 0-100 yang berarti baik.

\section{Strukturisasi Lembaga yang Terlibat} dalam Pelaksanaan Pengembangan Desa Mandiri Pangan di Kabupaten Bengkulu Tengah

Hasil identifikasi dan pendapat pakar diketahui bahwa lembaga yang terlibat dalam pengembangan desa mandiri pangan di Kabupaten Bengkulu Tengah, adalah : (1) Pembudidaya Pangan, (2) Pengolah Hasil Pangan, (3) Pemasar Hasil Pangan, (4) Balai Pembibitan, (5) Unit Pembenihan Rakyat (UPR), (6) Balai Benih Ikan (BBI), (7) Kelompok Tani/Ternak/Nelayan (8) Gapoktan, (9) KTNA, (10) Koperasi Dan UKM, (11) Lembaga Keuangan Mikro, (12) Lembaga Sosial, (13) Penyuluh, (14) Kementrian Pertanian, (15) Dinas Teknis, (16) Badan Ketahanan Pangan, (17) Bappeda, (18) Dinas Pekerjaan Umum, (19) BP4K, (20) Tokoh Masyarakat, (21) Kementrian 
Kelautan Dan Perikanan,

Disperindag.

Output ISM dari program ISM-Strella adalah berupa rangking masing-masing subelemen dan plot masing-masing subelemen kedalam empat sektor berserta koordinatnya. Adapun letak koordinat masing-masing menunjukkan plot masing sub-elemen ke dalam empat sektor. Berdasarkan keluaran program, maka dapat digambarkan plot masing-masing subelemen seperti pada Gambar 1.

Berdasarkan Reachability Matrix (RM) didapatkan nilai Driver-Power (DP) dan nilai Dependence (D) dalam menentukan klasifikasi sub-elemen dimana klasifikasi sub-elemen Lembaga Sosial, berada pada sektor I (AUTONOMOUS) yaitu subelemen dengan daya dorong lemah dan mempunyai ketergantungan yang rendah terhadap program (weak driver, weak dependent) (Marimin, 2004).

Untuk sektor II (DEPENDENT) yaitu sub-elemen yang mempunyai daya dorong lemah namun mempunyai ketergantungan yang kuat terhadap program (weak driver, strongly dependent) (Marimin, 2004), di tempati oleh Pengolah Hasil Pangan, Pemasar Hasil Pangan, Kelompok
Tani/Ternak/Nelayan, Koperasi dan UKM, Lembaga Keuangan Mikro, Gapoktan, KTNA, Unit Pembenihan Rakyat.

Sedangkan yang berada pada sektor III (LINKAGE) yaitu sub-elemen yang mempunyai daya dorong dan ketergantungan yang kuat terhadap program (strong driver, strongly dependent) (Marimin, 2004) adalah Pembudidaya Pangan, Disperindag.

Pada sektor IV (INDEPENDENT) yaitu subelemen yang mempunyai daya dorong yang kuat namun mempunyai ketergantungan yang lemah terhadap program (strong driver, weak dependent) (Marimin, 2004) adalah Kementrian Pertanian, Dinas Teknis, Badan Ketahanan Pangan, BP4K, Tokoh Masyarakat, Kementrian Kelautan Dan Perikanan, Balai Pembibitan, Balai Benih Ikan, Bappeda, Dinas Pekerjaan Umum, Penyuluh.

Berdasarkan rangking masing-masing sub-elemen maka dapat dibuat hierarki setiap elemen dimana subelemen dengan rangking yang lebih tinggi akan berada pada hierarki yang lebih rendah seperti pada Gambar 2. 


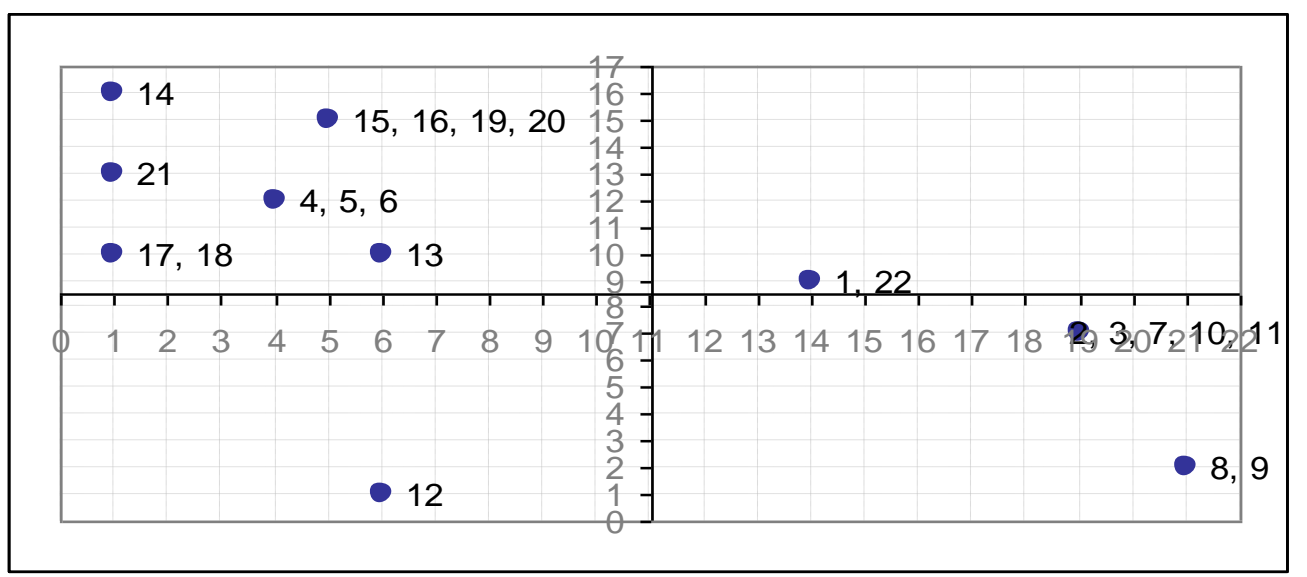

Keterangan:

\begin{tabular}{|c|c|c|c|c|c|}
\hline Sektor I & 12: & Lembaga Sosial & Sektor II & $\begin{array}{l}2 \\
3 \\
7 \\
10 \\
11 \\
8 \\
9\end{array}$ & $\begin{array}{l}\text { Pengolah hasil pangan } \\
\text { Pemasar Hasil Pangan } \\
\text { Kelompok Tani/Ternak/Nelayan } \\
\text { Koperasi dan UKM } \\
\text { Lembaga Keuangan Mikro } \\
\text { Gapoktan } \\
\text { KTNA }\end{array}$ \\
\hline Sektor III & $\begin{array}{l}1 \\
22\end{array}$ & $\begin{array}{l}\text { Pembudidaya } \\
\text { Pangan } \\
\text { Disperindag }\end{array}$ & $\begin{array}{l}\text { Sektor } \\
\text { IV }\end{array}$ & $\begin{array}{l}14 \\
15 \\
16 \\
19 \\
20 \\
21 \\
4 \\
5 \\
6 \\
17 \\
18 \\
13\end{array}$ & $\begin{array}{l}\text { Kementrian Pertanian } \\
\text { Dinas Teknis } \\
\text { Badan Ketahanan Pangan } \\
\text { BP4K } \\
\text { Tokoh Masyarakat } \\
\text { Kementrian Kelautan \& Perikanan } \\
\text { Balai Pembibitan } \\
\text { Unit Pembenihan Rakya } \\
\text { Balai Benih Ikan } \\
\text { BAPPEDA } \\
\text { Dinas Pekerjaan Umum } \\
\text { Penyuluh }\end{array}$ \\
\hline
\end{tabular}

Gambar 1. Matriks driver power-dependence lembaga yang terlibat dalam pelaksanaan pengembangan desa mandiri pangan di Kabupaten Bengkulu Tengah

Keberhasilan desa mandiri pangan di

Kabupaten Bengkulu Tengah memerlukan

komitmen yang tegas dari pemerintah.

Sebagai langkah awal dalam melaksanakan

komitmen adalah ditetapkannya Undang-

Undang yang secara eksplisit menyatakan kewajiban mewujudkan ketahanan pangan.

Penguatan kelembagaan ketahanan pangan di Bengkulu Tengah akan terwujud berkat tugas bersama, pemerintah, swasta dan masyarakat dari tingkat kabupaten sampai tingkat desaa sering muncul konsep. Di daerah telah terbentuk lembaga ketahanan pangan, namun tampaknya lembaga ini masih belum berfungsi optimal dan belum belibatkan berbagai unsur dalam masyarakat. Sehingga sering muncul konsep ketahanan pangan yang salah dengan menganggap ketahanan pangan identik dengan beras dan yang bertanggung jawab adalah Dinas Tanaman Pangan. 


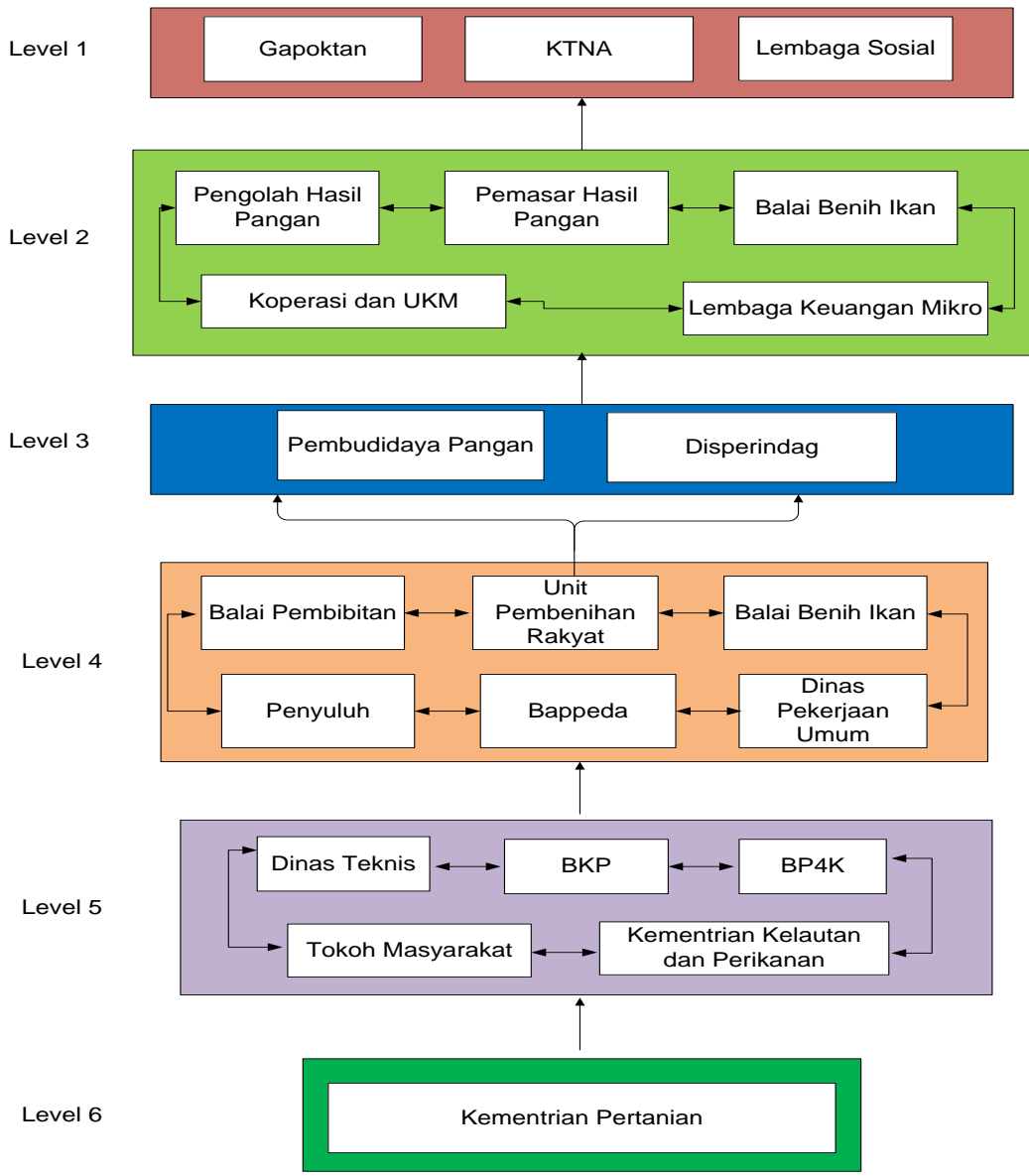

\section{Gambar 2. Diagram Model Struktural Lembaga yang Terlibat dalam Pengembangan Desa Mandiri Pangan di Kabupaten Bengkulu Tengah.}

Pemerintah Kabupaten Bengkulu Tengah terus berupaya mendorong mensosialisasikan kelembagaan tersebut dan mendorong keikutsertaan swasta dan masyarakat agar memiliki kesempatan berperan seluas-luasnya mewujudkan ketahanan pangan di Kabupaten Bengkulu Tengah. Sesuai dengan tugas yang diembannya, pemerintah pusat berperan memfasilitasi penciptaan kondisi yang kondusif melalui penetapan kebijakan makro dengan terwujudnya ketahanan pangan nasional serta memberi peluang kepada masyarakat dan swasta untuk berkiprah dalam pembangunan ketahanan pangan.

Berdasarkan informasi yang diperoleh dari lapangan dalam pengembangan desa mandiri pangan di kabupaten Bengkulu Tengah pembudidaya pangan, Balai Pembibitan, Balai Benih Ikan (BBI), Unit Pembenihan Rakyat (UPR), dan penyuluh mendapat dukungan dari Badan Ketahanan pangan (BKP) Kabupaten Bengkulu 
Tengah dalam pengembangan kualitas sumberdaya manusia, pembinaan dan penyuluhan, subsidi benih dan induk unggul terhadap pembudidaya pangan, temu usaha pelaku pangan dan berbagai lomba variasi makanan untuk mendukung ketahanan pangan.

Badan Ketahanan Pangan (BKP) juga bekerjasama dengan Dinas Teknis seperti Dinas Pertanian, Dinas Peternakan, Dinas Kelautan dan Perikanan serta Bappeda, dan Dinas PU bekerjasama dalam bentuk Rencana Program Jangka Menengah (RPJM) sebagai pedoman dalam penyusunan kegiatan pengembangan desa mandiri pangan. Dukungan Dinas Pekerjaan Umum (PU) diwujudkan dalam kegiatan upaya melaksanakan capaian produksi dan produktivitas seperti pengembangan infrastruktur jalan (aksesibilitas kawasan), pengembangan manajemen air, peningkatan sarana irigasi dan pembangunan infrastruktur dasar permukiman. Namun, hingga saat ini kerjasama antar anggota tim tersebut belum berjalan efektif. Untuk itu perlu peningkatan koordinasi dan sinkronisasi antar pihak yang terkait.

Di Kabupaten Bengkulu Tengah sebagian besar pembudidaya pangan telah tergabung dalam kelompok tani/ternak/nelayan dan KTNA, dukungan penguatan terhadap kelompok-kelompok ini seperti penyuluhan, peningkatan akses pembudidaya terhadap permodalan penyediaan benih dan bibit, peningkatan kualitas SDM, penyediaan sarana prasarana untuk mendukung sistem produksi, pengolahan dan pemasaran masih perlu ditingkatkan dan diperkuat.

Untuk kebutuhan bibit dan benih dalam usaha pengembangan desa mandiri pangan tersedia balai pembibitan, balai benih. Kinerja dari balai pembibitan dan balai benih ini sudah cukup bagus namun masih perlu ditingkatkan, agar dapat menyediakan benih baik dari segi jumlah, kualitas dan waktu.

Pengembangan desa mandiri pangan di Kabupaten Bengkulu Tengah bertumpu pada pembudidaya pangan serta kelembagaan pembudidaya pangan yang kuat dimana antar sub-sistem harus berjalan secara sinergi. Sebagai subelemen yang mempunyai daya dorong yang kuat, Disperindag sangat dibutuhkan untuk mendampingi pembudidaya pangan dalam memfasilitasi di bidang pengolahan dan pasar yaitu perindustrian dan perdagangan.

Pengolah Hasil Pangan, Pemasar Hasil Pangan, Kelompok Tani/Ternak/Nelayan, Koperasi dan UKM, Lembaga Keuangan Mikro, Gapoktan, KTNA menurut hasil RM (Reachability Matrix) berada pada sektor II (DEPENDENT). Menurut 
Marimin (2004), subelemen yang masuk pada sektor ini merupakan subelemen dengan daya dorong yang rendah namun memiliki ketergantungan yang kuat terhadap program (weak driver-strongly dependent).

Pada upaya pengembangan desa mandiri pangan permodalan sangat diperlukan untuk mendukung mandiri pangan. Pengembangan desa mandiri pangan di Kabupaten Bengkulu Tengah, belum terlihat peran berarti dari lembaga keuangan mikro (perbankan) maupun koperasi. Permodalan pembudidaya pangan sebagian besar berasal dari modal sendiri atau berasal dari pinjaman para tengkulak. Hal ini terjadi karena rumitnya birokrasi yang harus dilewati dan sulitnya persyaratan yang harus dipenuhi oleh pelaku usaha pangan untuk mendapatkan pinjaman dari lembaga perbankan.

Kabupaten Bengkulu Tengah dalam kegiatannya masih terbatas pada peningkatan produksi. Dalam kegiatan tersebut belum terdapat keterkaitan antara pembudidaya, pengolah dan pemasar hasil pangan secara berkelanjutan, hasil pangan sebagian besar masih dijual dalam bentuk segar. Jumlah produk pangan olahan baik dari jumlah maupun jenisnya pun masih sangat sedikit. Oleh karena itu, disamping peningkatan produktivitas dan produksi diperlukan peningkatan nilai tambah produk pangan melaui kegiatan diversifikasi olahan berbahan dasar pangan yang berdaya saing dan berorientasi pasar. Pada pengembangan desa mandiri, belum terlihat adanya peran yang signifikan dari Lembaga Sosial. Lembaga ini menurut hasil olahan RM (Reachability Matrix), berada pada sektor I (AUTONOMOUS). Sub-elemen yang masuk dalam sektor ini merupakan sub-elemen dengan daya dorong lemah dan mempunyai ketergantungan yang rendah terhadap program (Marimin, 2004). Untuk itu peran lembaga tersebut masih perlu ditingkatkan seperti peningkatan kerjasama antara masyarakat dengan pembudidaya pangan untuk menghindari terjadinya konflik. Lembaga sosial juga dapat berperan dalam kontrol sosial pada kegiatan-kegiatan pengembangan desa mandiri pangan yang bermanfaat bagi seluruh pelaku kegiatan pangan, berdampak positif dari segi sosial dan berkelanjutan secara ekologi.

Menurut Sutoyo, (2013), dalam melaksanakan pembangunan ketahanan pangan merupakan tanggung jawab pemerintah (pusat dan daerah) bersamasama dengan masyarakat. Dewan ketahanan pangan memfasilitasi pemerintah daerah agar memiliki kapasitas dalam menangkap aspirasi masyarakat serta memfasilitasi masyarakat agar mampu mengembangkan perannya secara 
maksimal dalam mewujudkan ketahanan pangan. Pada saat ini sangat diperlukan kerjasama antara pemerintah dan masyarakat secara lebih intensif, sinergis dan transparan sesuai dengan tanggung jawab dan kemampuannya masing-masing.

\section{KESIMPULAN}

Hasil olahan dengan Rap-Demangan diketahui nilai indeks keberlanjutan pada pengembangan desa mandiri pangan di Kabupaten Bengkulu Tengah yaitu sebesar 75,6 dalam skala keberlanjutan 0-100 yang berarti baik.

Struktur kelembagaan lembaga yang terlibat dalam desa mandiri pangan adalah sub-elemen lembaga sosial, berada pada sektor I (AUTONOMOUS), Untuk sektor II (DEPENDENT), di tempati oleh Pengolah Hasil Pangan, Pemasar Hasil Pangan, Kelompok Tani/Ternak/Nelayan, Koperasi dan UKM, Lembaga Keuangan Mikro, Gapoktan, KTNA, Unit Pembenihan Rakyat, Sedangkan yang berada pada sektor III (LINKAGE) adalah Pembudidaya Pangan, Disperindag. Pada sektor IV (INDEPENDENT) yaitu adalah Kementrian Pertanian, Badan Ketahanan Pangan, Dinas Teknis, Bp4k, Tokoh Masyarakat, Kementrian Kelautan Dan Perikanan, Balai Pembibitan, Balai Benih Ikan, Bappeda, Dinas Pekerjaan Umum.

\section{SARAN}

Pemerintah daerah agar lebih responsif, konsisten dan berani mengambil, membuat kebijakan yang pro masyarakat pembudidaya panagn serta peningkatan koordinasi antar sektor atau dinas teknis di daerah.

Pihak swasta diharapkan mampu membuka peluang kerjasama atau bermitra dengan para pembudidaya pangan yang menguntungkan dalam upaya pengembangan desa mandiri pangan yang berkelanjutan.

\section{DAFTAR PUSTAKA}

Abdoellah, O.S. 2010. Pembangunan Berkelanjutan Gagasan dan Implementasi. Universitas Sumatera Utara.

BKP, Kementan. 2012. Pedoman Umum Program Aksi Desa Mandiri Pangan. Badan Ketahanan Pangan. Departemen Pertanian.

Dewi I.K, 2011. Faktor-faktor yang Berpengaruh Terhadap Keberlanjutan Kawasan Permukiman di Daerah Aliran Sungai (DAS) Ciliwung Hulu Kabupaten Bogor. Ekologia, Vol 11 No.1, April 2011: 12-20.

Sutoyo, Adi. 2013. Implementasi program Aksi Mandiri Pangan di Propinsi Bengkulu. DIA. Jurnal Administrasi Publik, Vol 11 No.1 Tahun 2013, Hal: 93-116.

Wikipedia Indonesia. 2012.Pembangunan Berkelanjutan. http://humas UGM Seminar Pemodelan Desa Mandiri Pangan.pdf. Diakses 21 Oktober 2015.

Yusvianty. 2010. Perencanaan Pembangunan Wil ayah Pesisir (Studi Kasus Kabupaten Pesisir Selatan). Tesis.Universitas Andalas. 